\title{
Investigation of Presence of SAP3 Virulence Gene in Candida albicans Strains Isolated from Patients with Vulvovaginal Candidiasis
}

\author{
Ahmad Jabrodini ${ }^{1, *}$, Seyedeh Faezeh Taghavi ${ }^{2}$ \\ ${ }^{1}$ Instructor, Department of Laboratory Sciences, School of Paramedical, Gerash University of Medical Sciences, Gerash, Iran \\ ${ }^{2}$ BSc, Department of Laboratory Sciences, School of Paramedical, Gerash University of Medical Sciences, Gerash, Iran
}

* Corresponding Author: Ahmad Jabrodini, Department of Laboratory Sciences, School of Paramedical, Gerash University of Medical Sciences, Gerash, Iran.Email: ahmad.jabrodini@gmail.com

\begin{tabular}{|c|c|}
\hline & Abstract \\
\hline $\begin{array}{l}\text { Received: } 12.09 .2018 \\
\text { Accepted: } 10.11 .2018\end{array}$ & \multirow{3}{*}{$\begin{array}{l}\text { Background and Objective: Vulvovaginal Candidiasis (VVC) affect } \\
\text { millions of women annually. Candida albicans is the most common cause of } \\
\text { VVC. Secreted aspartyl proteinases (SAPs) are among the most important } \\
\text { virulence factors in Candida species. The SAP3 enzyme is effective in the } \\
\text { initial development of VVC infection due to its role in the adhesion of } \\
\text { Candida albicans. The aim of this study was to determine the presence of } \\
\text { SAP3 gene in Candida albicans strains isolated from patients with } \\
\text { Vulvovaginal Candidiasis. } \\
\text { Materials and Methods: In this cross-sectional study, vaginal secretion } \\
\text { samples were collected from } 268 \text { vaginitis patients referred to } \\
\text { Amiralmomenin Hospital of Gerash city, Fars province, Iran from March } \\
\text { to August } 2018 \text {. After direct microscopic examination, all samples were } \\
\text { cultured on sabouraud dextrose agar medium with chloramphenicol } \\
\text { (50mg/L). Candida strains were identified using standard phenotypic and } \\
\text { sugar assimilation tests (API20C). Genomic DNA extraction and the } \\
\text { presence of SAP3 gene were performed using chloroform-phenol-isoamyl } \\
\text { alcohol and polymerase chain reaction (PCR) methods, respectively. } \\
\text { Results: Out of } 268 \text { samples, } 79 \text { (29.47\%) cases were positive for Candida } \\
\text { species under direct microscopy and culture results. } 48 \text { (60.75\%) and } \\
31 \text { (39.24\%) Candida albicans strains and Non-albicans candida species } \\
\text { were isolated, respectively. The results of PCR showed the presence of SAP3 } \\
\text { gene in } 47 \text { (97.91\%) Candida albicans strains. } \\
\text { Conclusion: It can be concluded that Candida albicans were more likely to } \\
\text { cause Vulvovaginal than other Candida species. The explanation for this is } \\
\text { the presence of the SAP3 gene in most Candida albicans strains. } \\
\text { Keywords: Candida albicans, SAP3 Gene, Polymerase Chain Reaction, } \\
\text { Vulvovaginal Candidiasis }\end{array}$} \\
\hline $\begin{array}{l}\text { How to Cite this Article: } \\
\text { Jabrodini A, Taghavi SF. } \\
\text { Investigation of Presence of } \\
\text { SAP3 Virulence Gene in } \\
\text { Candida albicans Strains } \\
\text { Isolated from Patients with } \\
\text { Vulvovaginal Candidiasis. } \\
\text { Avicenna J Clin Med. 2018; } \\
\text { 25(3): 159-164. DOI: 10.21859/ } \\
\text { ajcm.25.3.159 }\end{array}$ & \\
\hline & \\
\hline
\end{tabular}




\title{
بررسى وجود زن بيمارىزاى SAP3 در سويهاى كانديلا آلبيكنس جداشده از

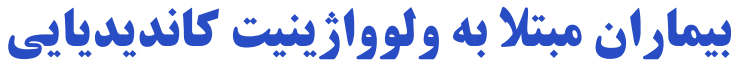

\author{
احمد جبر الدينى ا:*ق، سيده فائزه تقوى

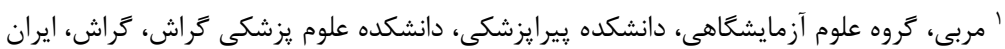

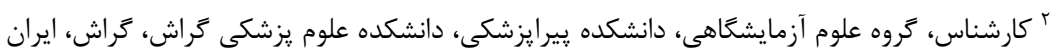 \\ * نويسنده مسئول: احمد جبرالدينى، كروه علوم آزمايشكاهى، دانشكده بيرايزشكى، دانشكده علوم يزشكى تراش، كراش، ايران. \\ ايميل: ahmad.jabrodini@gmail.com
}

\begin{tabular}{|c|c|}
\hline 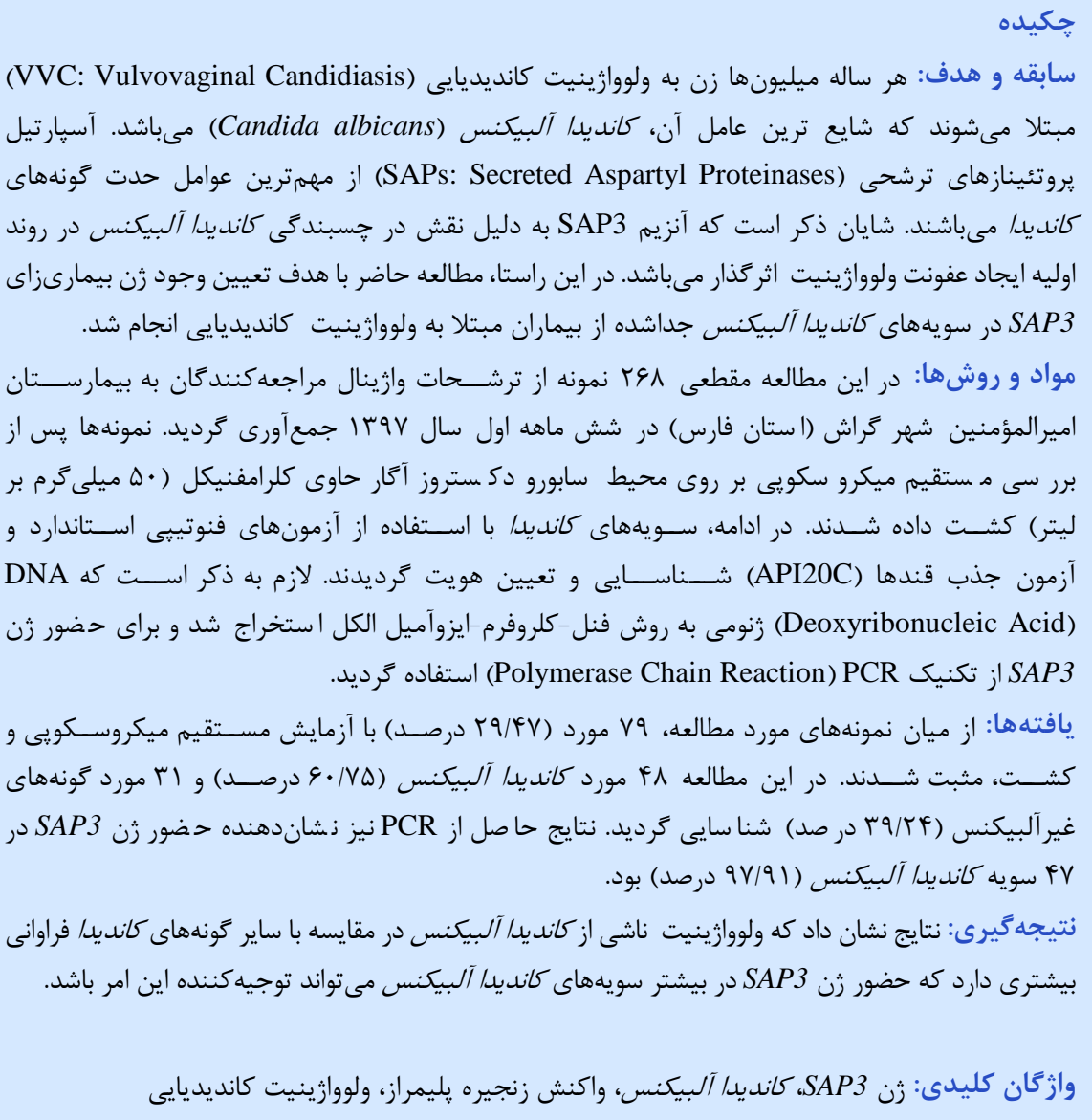 & 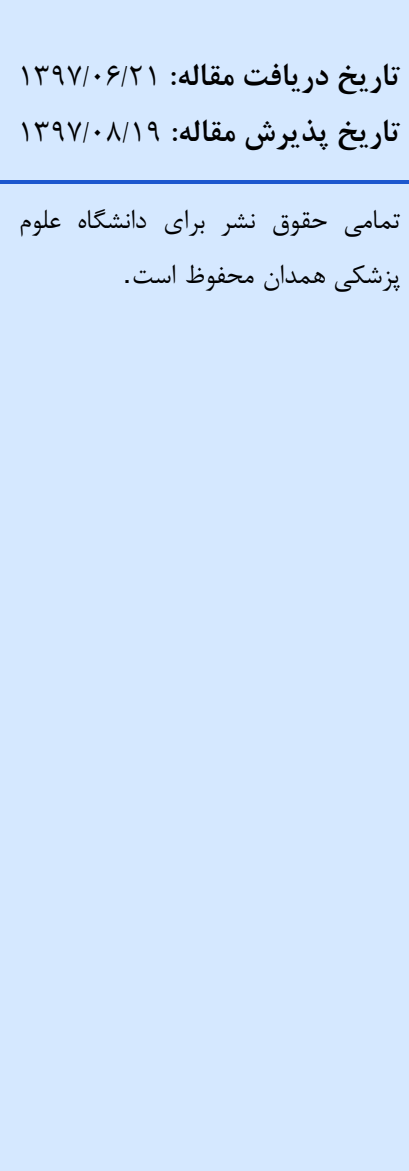 \\
\hline
\end{tabular}

مقلdمه

كوارشى و تنفسى، حفره ناخن و : يوست مستقر مىباشند [F]

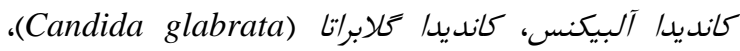

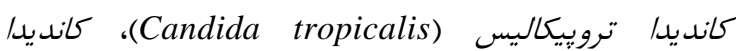

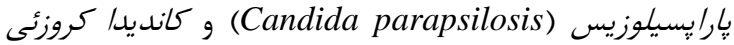
مهيمترين عوامل ايجادكننده Candida krusei)

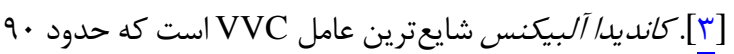

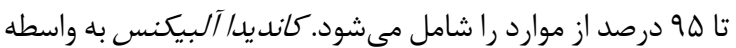
عوامل حدت خود از قبيل جسبندكى به سطح سلولها، تشكيل
ولووازينيت كانديديايى (VVC) يك عفونت قارجى شايع در

زنان است كه به دليل رشد غيرطبيعى مخمرهاى جنس كانديدا

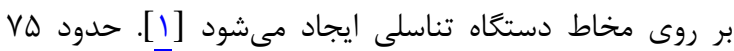

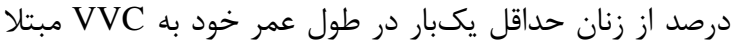

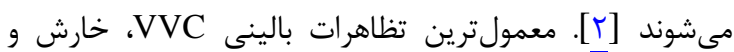

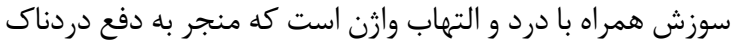

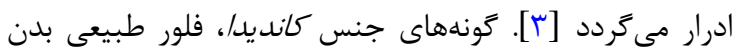
انسان هستند و در سطوح مخاطى دستخاه تناسلى- ادرارى، 
دموكر افيك، نمونهبردارى با استفاده از اسيكولوم و دو عدد سواب

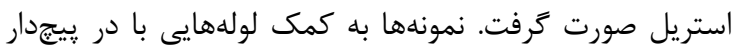

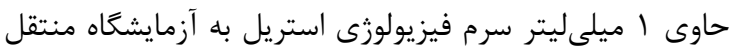
شدند. با مشاهده مخمرهاى جوانهدار به همراه ميسليوم كاذب و

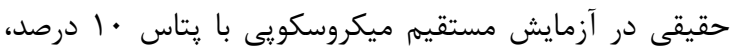

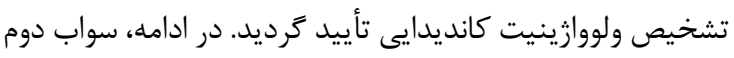

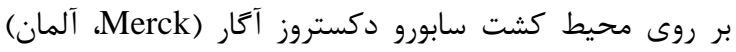

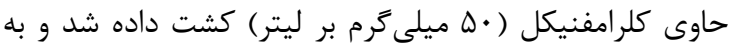

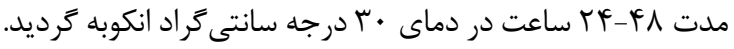

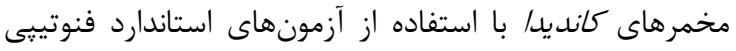

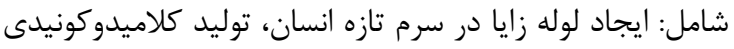

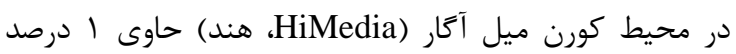
توئين •^م و كشت بر روى محيط كروم كانديد/ آكار (Merck)،

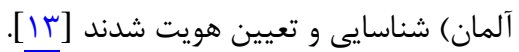

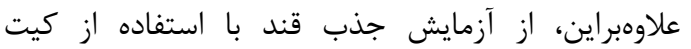

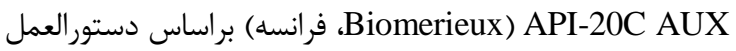
شركت سازنده براى شناسايى گونههاى كانديداى غير آلبيكنس

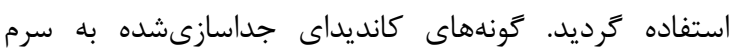
فيزيولوزى حاوى • r درصد كليسرول منتقل شدند و براى مراحل

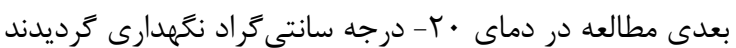

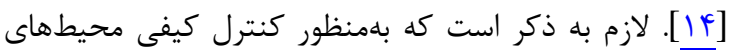
كشت و آزمونهاى فنوتيبى از سويههاى استاندارد كانديدا آلبيكنس ATCC10231 و كانديدا كلابراتا ATCC90030

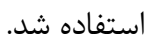

استخراج DNA و واكنش زنجيرهاى يليمراز (PCR)

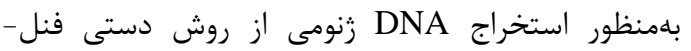

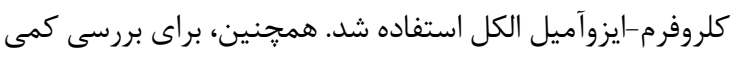

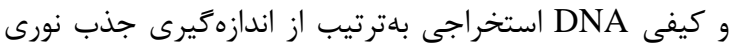
(OD260/OD280>1/7)

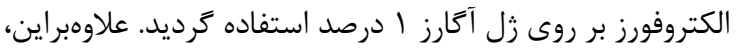

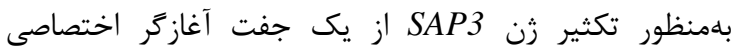
بهدستآمده از مطالعه قبلى استفاده شد [ه]. زن

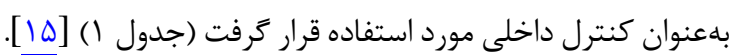

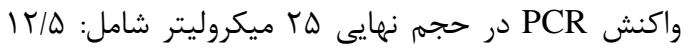

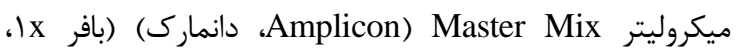

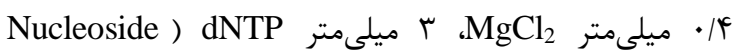
و و • (Triphosphate
هايف، تغيير شكل ظاهرى (Phenotype Switching)، تشكيل

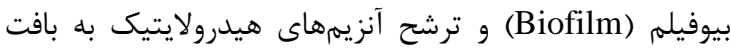

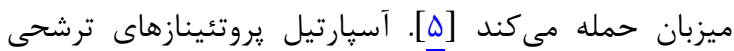

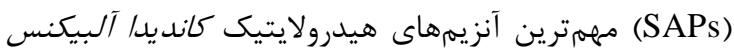

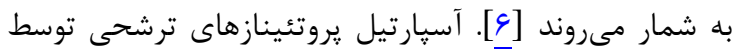

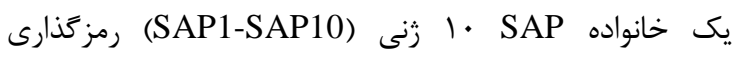

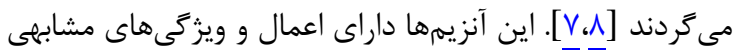

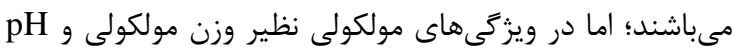

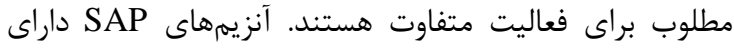

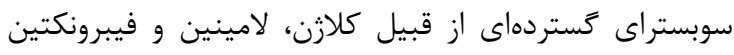

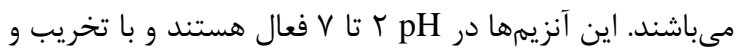
شكستن غشاى مخاطى باعث تسهيل در تهاجم و مستقرشدن آنسان

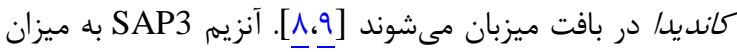

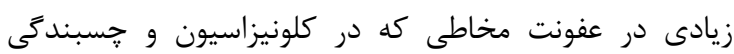
كانديدا آلبيكنس به سلول هاى إيى تليال نقش دارد، بيان مئشون

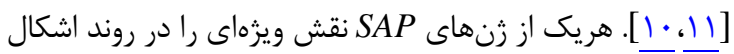

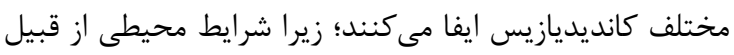

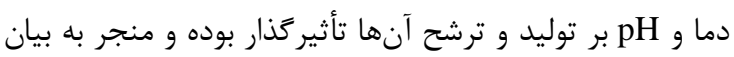

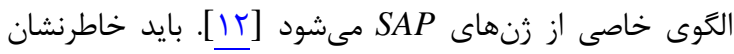

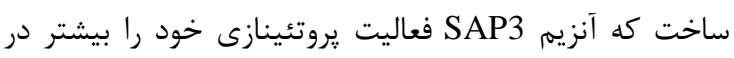
شرايط اسيدى (•/pH

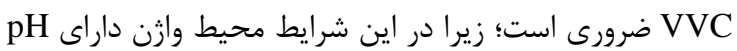

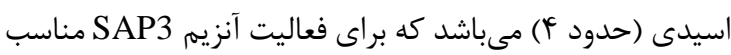

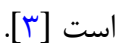

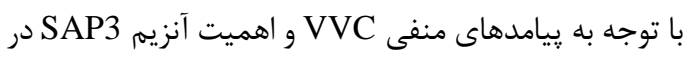

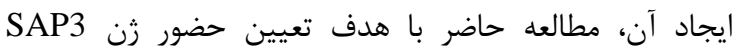

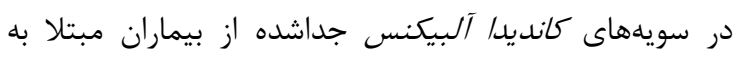
ولووازينيت كانديديايى صورت كرفت.

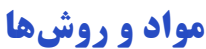 جمعآورى نمونهها و شناسا يیى كونه ماى كاندانديدا}

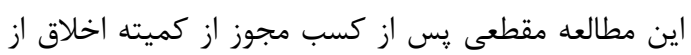

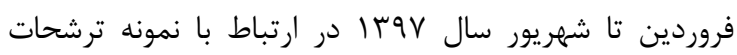

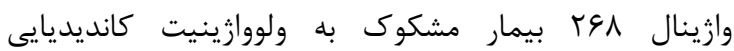

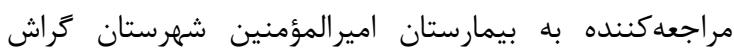

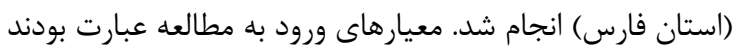

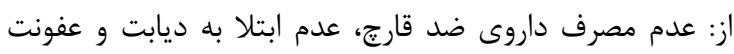

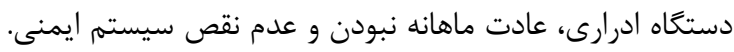

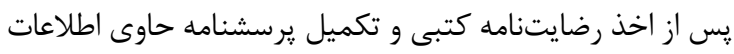

جدول ا: توالى آغازَرهاى مورد استفاده به همراه اندازه قطعات محصول PCR

\begin{tabular}{|c|c|c|c|}
\hline منبع & طول قطعه محصول (bp) & توالى آغازتر '33 & 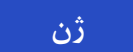 \\
\hline$\underline{\Delta}$ & וTr & $\begin{array}{l}\text { CCTTCTCTA AAATTATGGATTGGAAC } \\
\text { TTGATTTCACCTTGGGGACCAGTAACATTT }\end{array}$ & $\begin{array}{l}\text { SAP3(F) } \\
\text { SAP3(R) }\end{array}$ \\
\hline 10 & 190 & $\begin{array}{l}\text { CCA GCT TTC TAC GTT TCC } \\
\text { CTG TAA CCA CGT TCA GAC }\end{array}$ & $\begin{array}{l}\operatorname{ACT1}(\mathrm{F}) \\
\operatorname{ACT1}(\mathrm{R})\end{array}$ \\
\hline
\end{tabular}


ها • ميكروليتر از هر آغازَر و r ميكروليتر DNA الكو بود و حجم

سالانه ميليونها زن به ولووازينيت كانديديايى مبتلا

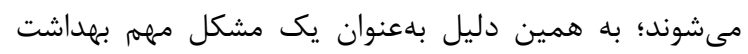

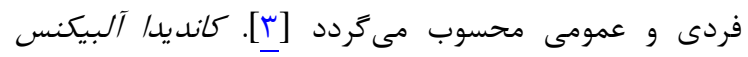

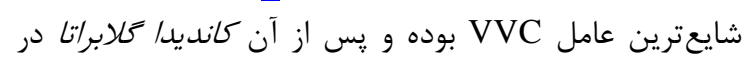
درجه دوم قرار دارد [ifli]. در مطالعه حاضر از د

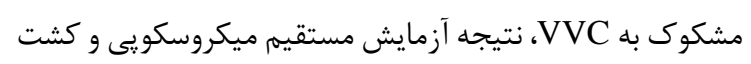

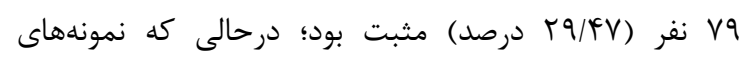

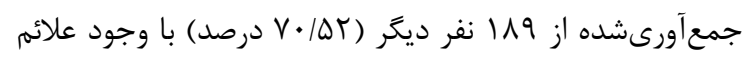

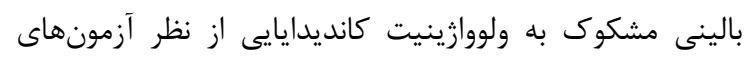

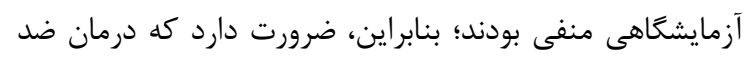

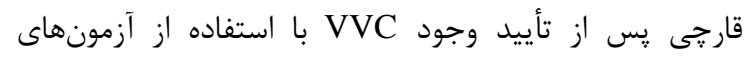

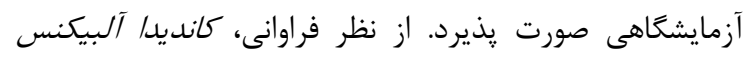

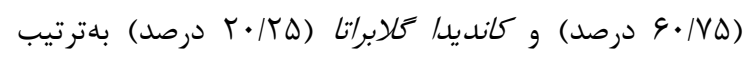

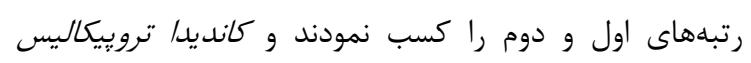

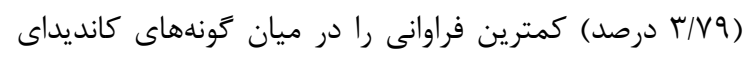
جداسازىشده به خود اختصاص داد. در مطالعه عباسى نجات و همكاران كه در شهر گركان انجام

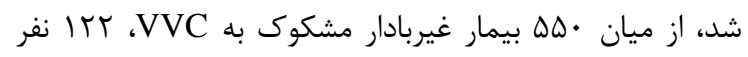

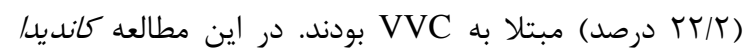

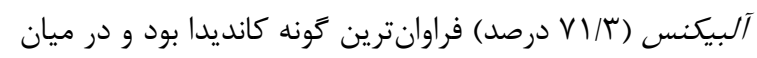

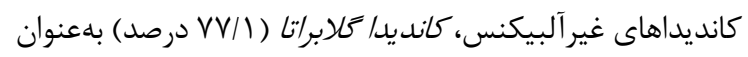

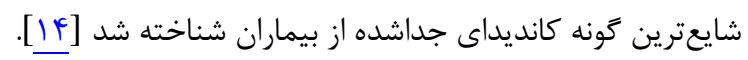

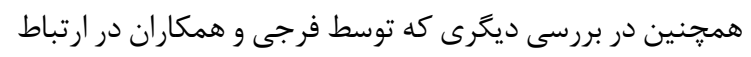

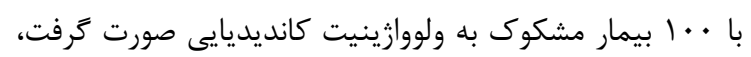

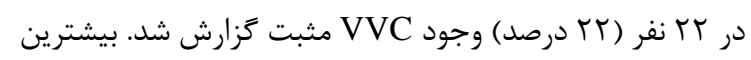

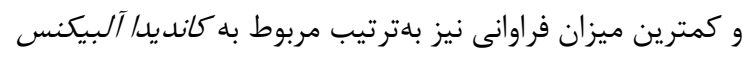

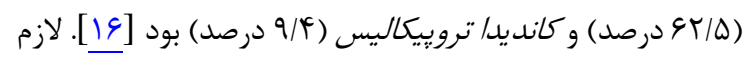
به ذكر است كه يافتههاى حاصل از مطالعات فوق با نتايج بلهدستآمده از مطالعه حاضر مطابقت و همخوانى دارند.

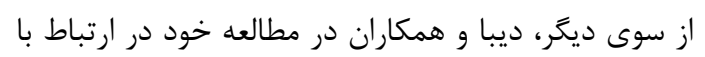

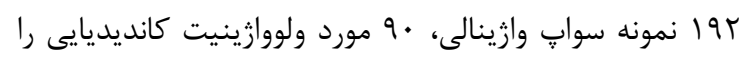

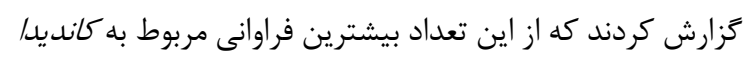

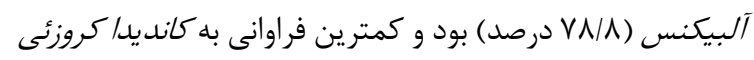

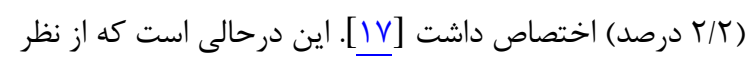

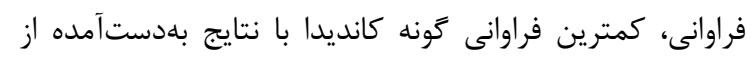
مطالعه حاضر همخوانى ندارد.

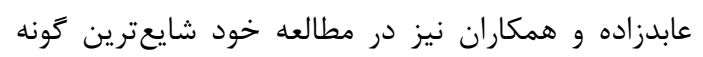

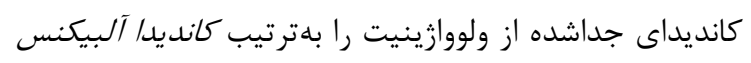

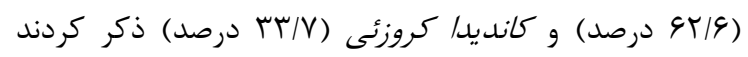

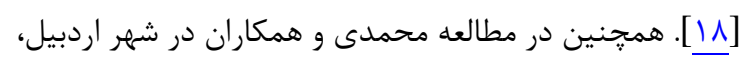

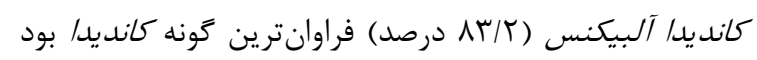

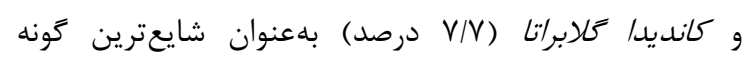

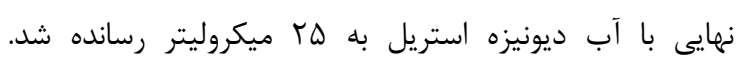

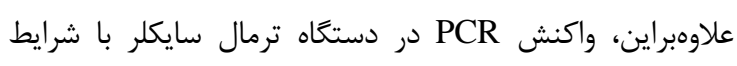

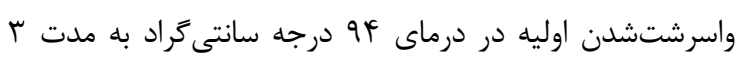

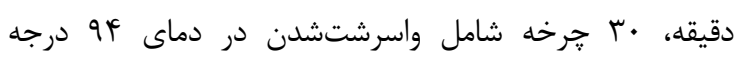
سانتى

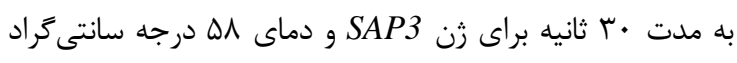

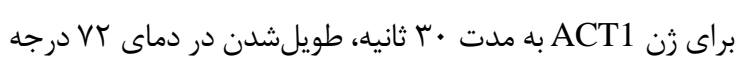

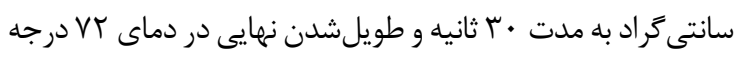

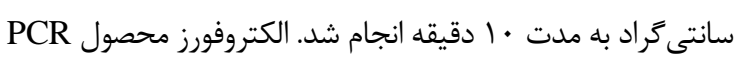

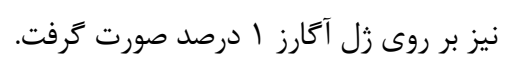

1. بافته ه. از

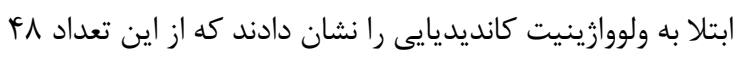

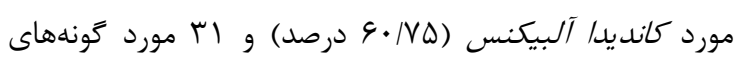

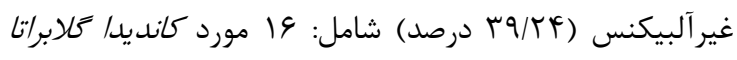

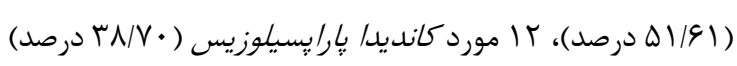

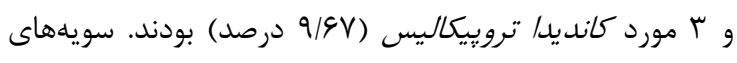

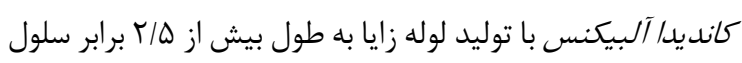

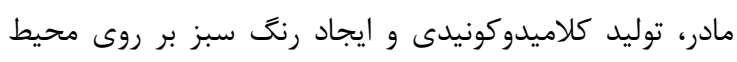

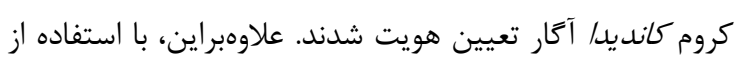
جذب قندهاى مختلف و ايجاد كلنى رنكى بر روى محيط كروم ناند

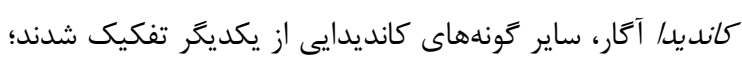

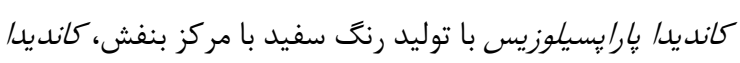

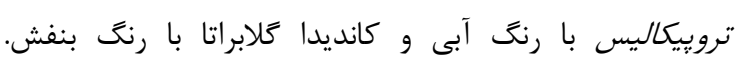

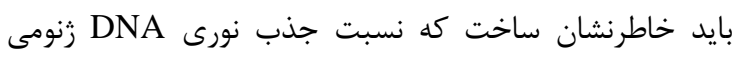

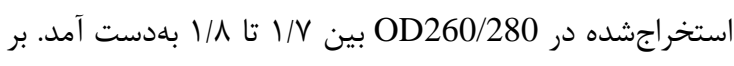

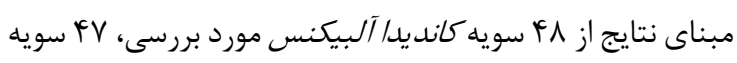

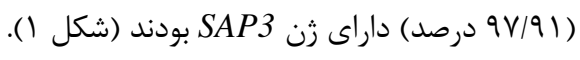

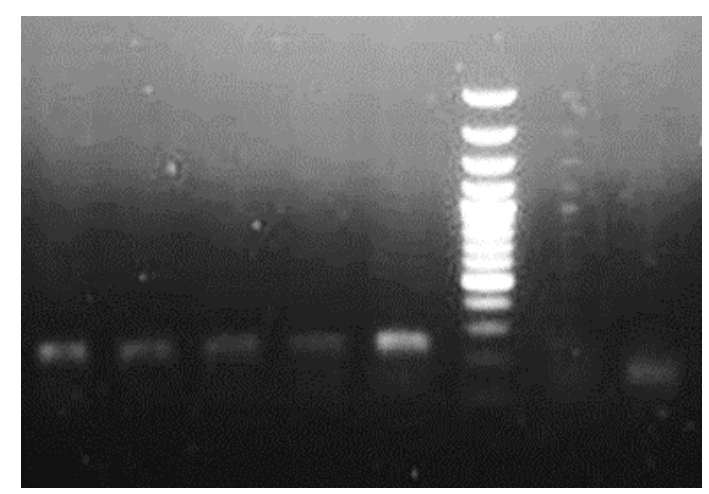

شكل ا: الكتروفورز محصول PCR زن SAP3 سويههاى كانديدا

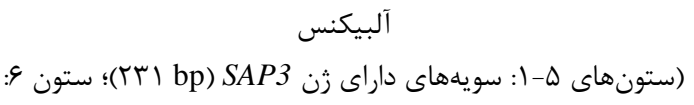

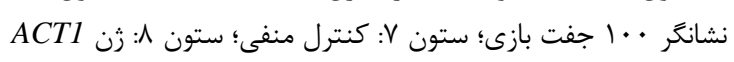
(() $90 \mathrm{bp})$ 
و فعاليت مطلوب آنزيم SAP3 در PH=r-F و نيز براساس نتايج حاصل از مطالعه حاضر كه نشاندهنده حضور زن آن

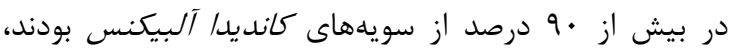

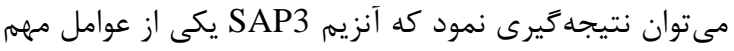

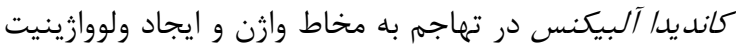
است. ذكر اين نكته ضرورت دارد كه رعايت بهداشت فردى و عدم استفاده از لباسهاى زير تندَ به ميه ميزان زيادى از بروز

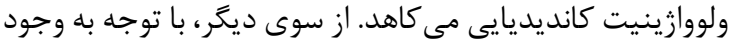

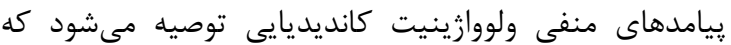
مراكز بهداشتى - درمانى معيارهاى تشخيصى عفونت را بر يايه

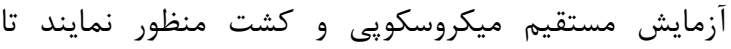

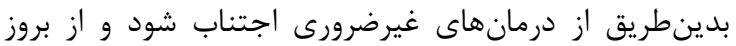
مقاومت دارويى جلو گيرى گردد.$$
\text { تشك و قلرواذى }
$$

اين مقاله حاصل طرح يزوهشى مصوب دانشكده علوم

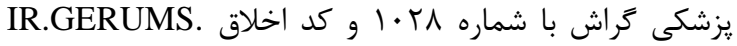

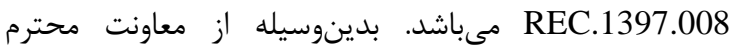
تحقيقات و بخش قارجشناسى دانشكده به دليل همكارى در

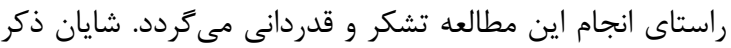
است كه نويسندكان هيج گونه تعارض منافعى با نتايج مطالعه

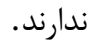

\section{REFERENCES}

1. Chew SY, Than LT. Vulvovaginal Candidosis: contemporary challenges and the future of prophylactic and therapeutic approaches. Mycoses. 2016;59(5):262-73. PMID: 26765516 DOI: $10.1111 /$ myc. 12455

2. Kenechukwu FC, Attama AA, Ibezim EC, Nnaman PO, Umeyor CE, Uronnachi EM, et al. Surface-modified mucoadhesive microgels as a controlled release system for miconazole nitrate to improve localized treatment of vulvovaginal Candidiasis. Eur J Pharm Sci. 2018;111:35875. PMID: 28986195 DOI: 10.1016/j.ejps.2017.10.002

3. Goncalves B, Ferreira C, Alves CT, Henriques M, Azeredo J, Silva S. Vulvovaginal Candidiasis: epidemiology, microbiology and risk factors. Crit Rev Microbiol. 2016;42(6):905-27. PMID: 26690853 DOI: 10.3109/ 1040841X.2015.1091805

4. Anaissie EJ, McGinnis MR, Pfaller MA. Clinical mycology. $2^{\text {nd }}$ ed. New York: Elsevier; 2009. P. 197-231.

5. Lima JS, Braga KR, Vieira CA, Souza WW, Chávez-Pavoni JH, Araújo CD, et al. Genotypic analysis of secreted aspartyl proteinases in vaginal Candida albicans isolates. J Bras Patol Med Lab. 2018;54(1):28-33. DOI: 10.5935/16762444.20180006

6. Rahayu RP, Widiyanti P. SAP3 gene expression as diagnostic marker of oral Candidiasis in hiv/aids patients. J Int Dental Med Res. 2017;10(1):156-61.

7. Correia A, Lermann U, Teixeira L, Cerca F, Botelho S, Costa $\mathrm{RM}$, et al. Limited role of secreted aspartyl proteinases Sap1 to Sap6 in Candida albicans virulence and host immune response in murine hematogenously disseminated Candidiasis. Infect Immun. 2010;78(11):4839-49. PMID: 20679440 DOI: 10.1128/IAI.00248-10

8. Coutinho HD. Factors influencing the virulence of Candida spp. West Indian Med J. 2009;58(2):160-3. PMID: 21866603

9. Hernando FL, Calvo E, Abad A, Ramírez A, Rementería A, Sevilla MJ, et al. Identification of protein and mannoprotein antigens of Candida albicans of relevance for the
غيرآلبيكنسى گزارش گرديد [11ا]. قابل ذكر است كه نتايج مطالعه حاضر با يافتههاى مطالعات فوق همسويى دارد. شيوع

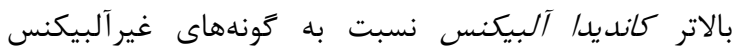
مى تواند به دليل وجود زنهاى SAP و توليد و ترشح آنزيمهاى SAP1-10

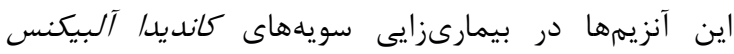
تأثير حذار است [؟].

يافتههاى بهدستآمده از بررسى حضور زن SAP3 در مطالعه حاضر نشاندهنده حضور اين زن در FV سويه كانديدا آلبيكنس ( 9V/91 درصد) بودند. در اين ارتباط ليما و همكاران

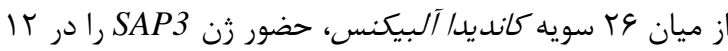

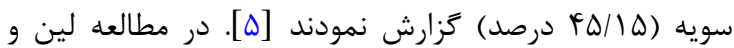
همكاران نيز بيشترين و كمترين فراوانى بهترتيب مربوط به

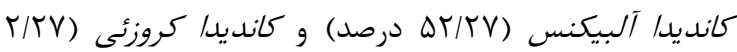
درصد) بود و حضور زن SAP3 در • ب سويه كانديدا آلبيكنس

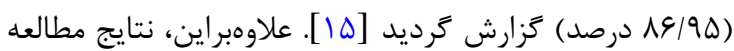

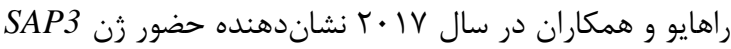
در •ه درصد از سويههاى كانديدا آلبيكنس جداشده از بيماران بودند [c] نتيجهة تيرى با توجه به اسيدىبودن pH وازن در ولووازينيت كانديديايى

serodiagnosis of invasive Candidiasis. Int Microbiol. 2007;10(2):103-8. PMID: 17661288

10. Liu Y, Mittal R, Solis NV, Prasadarao NV, Filler SG, Mechanisms of Candida albicans trafficking to the brain. PLoS Pathog. 2011;7(10):1002305. PMID: 21998592 DOI: 10.1371/journal.ppat.1002305

11. Hube B, Monod M, Schofield DA, Brown AJ, Gow NA. Expression of seven members of the gene family encoding secretory aspartyl proteinases in Candida albicans. Mol Microbiol. 1994;14(1):87-99. PMID: 7830564

12. Li W, Yu D, Gao S, Lin J, Chen Z, Zhao W. Role of Candida albicans-secreted aspartyl proteinases (Saps) in severe early childhood caries. Int J Mol Sci. 2014;15(6):10766-79. PMID: 24933640 DOI: $10.3390 /$ ijms150610766

13. Mohammadi-Ghalehbin B, Javanpour Heravi H, Arzanlou M, Sarvi MR. Prevalence and antibiotic resistance pattern of candida spp. isolated from pregnant women referred to health centers in Ardabil, Iran. J Ardabil Univ Med Sci. 2017;16(4):409-21. [Persian]

14. Abbasi Nejat Z, Farahyar S, Falahati M, Ashrafi Khozani M, Hosseini A, Faiazy A, et al. Molecular identification and antifungal susceptibility pattern of non-albicans Candida species isolated from vulvovaginal candidiasis. Iran Biomed J. 2017;22(1):33-41. PMID: 28688376

15. Lin N, Feng J, Tu Y, Feng A. Expression of Candida albicans secreted aspartyl proteinase in acute vaginal candidiasis. J Huazhong Univ Sci Technol Med Sci. 2007;27(3):333-5. PMID: 17641856 DOI: 10.1007/s11596-007-0330-8

16. Faraji R, Rahimi MA, Nazari N, Asadi N, Dehghani Firoozabadi A, Negahdary $\mathrm{M}$, et al. Isolation identification and susceptibility of Candida species isolated from diabetic women referred to Kermanshah diabetes research center (KDRC) in 2010. Iran J Med Microbiol. 2015;9(3):66-70. [Persian]

17. Diba K, Namaki A, Ayatolahi H, Hanifian H. Comparison of biochemical and molecular methods for the identification of 
candida species causing vulvovaginal candidiasis and recurring vulvovaginal candidiasis. Iran J Med Microbiol. 2014;8(3):45-50. [Persian]

18. Abedzadeh AH, Dakhili M, Haghighi N, Khalilian M. An investigation of the prevalence of Candida species in women referring to health center of Qom province, Iran. Qom Univ Med Sci J. 2016;9(12):65-71. [Persian] 